\title{
Donor levels of the divacancy-oxygen defect in silicon
}

\author{
V. P. Markevich, ${ }^{1, a)}$ A. R. Peaker, ${ }^{1}$ B. Hamilton, ${ }^{1}$ S. B. Lastovskii, ${ }^{2}$ and L. I. Murin ${ }^{2}$ \\ ${ }^{1}$ Photon Science Institute, the University of Manchester, Manchester M13 9PL, United Kingdom \\ ${ }^{2}$ Scientific-Practical Materials Research Center of NAS of Belarus, Minsk 220072, Belarus
}

(Received 19 July 2013; accepted 27 August 2013; published online 2 January 2014)

\begin{abstract}
The elimination of divacancies $\left(\mathrm{V}_{2}\right)$ upon isochronal and isothermal annealing has been studied in oxygen-rich p-type silicon by means of deep level transient spectroscopy (DLTS) and high resolution Laplace DLTS. Divacancies were introduced into the crystals by irradiation with 4 or $6 \mathrm{MeV}$ electrons. The temperature range of the divacancy disappearance was found to be $225-300{ }^{\circ} \mathrm{C}$ upon $30 \mathrm{~min}$ isochronal annealing in the samples studied. A clear anti-correlation between the disappearance of $\mathrm{V}_{2}$ and the appearance of two hole traps with activation energies for hole emission of $0.23 \mathrm{eV}$ and $0.08 \mathrm{eV}$ was observed. It is argued that these traps are related to the first and second donor levels of the divacancy-oxygen $\left(\mathrm{V}_{2} \mathrm{O}\right)$ complex, respectively. Significant electric field enhancement of the hole emission from the second donor level of the $\mathrm{V}_{2} \mathrm{O}$ center occurred in the diodes studied. It is shown that in the range of electric field from $4 \times 10^{3}$ to $1.2 \times 10^{4} \mathrm{~V} / \mathrm{cm}$ the emission enhancement is associated with phonon-assisted tunnelling. () 2014 AIP Publishing LLC. [http://dx.doi.org/10.1063/1.4837995]
\end{abstract}

\section{INTRODUCTION}

The divacancy $\left(\mathrm{V}_{2}\right)$ is a fundamental and technologically important defect in silicon. It influences the electrical and optical properties of Si crystals and being an effective recombination center affects the minority carrier life time and, consequently, performance of bipolar devices, radiation detectors and solar cells. ${ }^{1-3} \mathrm{~V}_{2}$ is induced in silicon by irradiation with high energy particles (electrons, neutrons, ions, etc.). ${ }^{4,5}$ It has been shown recently that divacancies can be introduced in significant concentrations into Si materials during technological steps used in solar cell production. ${ }^{3} \mathrm{~V}_{2}$ is formed either as a multiple displacement defect in the primary radiation damage event or as a result of interaction between two monovacancies. The two vacancies in the complex are positioned at adjacent lattice sites. ${ }^{4}$ The centre can exist in four charge states from the doubly negatively charged to the singly positively charged and introduces three deep levels, $\mathrm{V}_{2}(-2 /-), \mathrm{V}_{2}(-/ 0)$, and $\mathrm{V}_{2}(+/ 0)$, into the band gap located at $E_{\mathrm{c}}-0.24 \mathrm{eV}, E_{\mathrm{c}}-0.42 \mathrm{eV}$, and $E_{\mathrm{v}}+0.19 \mathrm{eV}$, respectively. ${ }^{1-9}$

It has been shown that divacancies can migrate rather long distances prior to dissociation. ${ }^{4}$ The activation energy for the diffusion of $\mathrm{V}_{2}$ has been found to be about $1.3 \mathrm{eV} .^{4,10-12}$ The migrating $\mathrm{V}_{2}$ can interact with other imperfections in the Si lattice. In particular, oxygen atoms were found to be effective traps for $\mathrm{V}_{2}$, and the divacancy-oxygen interaction was shown to be the main mechanism of the $\mathrm{V}_{2}$ elimination upon annealing of irradiated Czochralski-grown $(\mathrm{Cz}) \mathrm{Si}$ crystals. ${ }^{4,9,10,13-17}$ An EPR Si-A14 signal and an absorption line at $833.4 \mathrm{~cm}^{-1}$ have been assigned to a complex incorporating the divacancy and an oxygen atom $\left(\mathrm{V}_{2} \mathrm{O}\right){ }^{14,16}$ Deep level transient spectroscopy (DLTS) studies on irradiated and annealed n-type $\mathrm{Si}$ crystals have shown that the $\mathrm{V}_{2} \mathrm{O}$ center possesses two

\footnotetext{
${ }^{a)}$ e-mail: V.Markevich@manchester.ac.uk
}

acceptor levels at $E_{\mathrm{c}}-0.23 \mathrm{eV}$ and $E_{\mathrm{c}}-0.47 \mathrm{eV} .^{9,10,17}$ In p-type $\mathrm{Si}$ crystals a level at $E_{\mathrm{v}}+0.24 \mathrm{eV}$, which appeared simultaneously with the disappearance of $\mathrm{V}_{2}$ upon annealing, has been assigned to a donor level of the $\mathrm{V}_{2} \mathrm{O}$ complex. ${ }^{15}$ We have argued in a recent work that in addition to the first donor level at $E_{\mathrm{v}}+0.236 \mathrm{eV}$ the $\mathrm{V}_{2} \mathrm{O}$ center possesses a second donor level at $E_{\mathrm{v}}+0.087 \mathrm{eV}{ }^{18}$ The assignment of the above level to $\mathrm{V}_{2} \mathrm{O}$ has, however, been questioned recently. ${ }^{19,20}$ Bearing in mind that the $\mathrm{V}_{2} \mathrm{O}$ center is a technologically important defect, which is thought to be responsible for the degradation of silicon based particle detectors, ${ }^{21}$ we have carried out a detailed study of divacancy annealing in oxygen-rich p-type Si crystals and obtained conclusive information on electronic properties of the donor levels of the $\mathrm{V}_{2} \mathrm{O}$ defect.

\section{EXPERIMENTAL DETAILS}

The $\mathrm{n}^{+}-\mathrm{p}-\mathrm{p}^{+}$diodes used in this study were produced on boron-doped epi-Si $(\rho \approx 20 \Omega \cdot \mathrm{cm})$, which was grown on highly boron-doped $(\rho \approx 0.005 \Omega \cdot \mathrm{cm}) \mathrm{Cz}-\mathrm{Si}$ wafers. The diodes were formed by implantation of phosphorus ions with subsequent annealing at $1150^{\circ} \mathrm{C}$ in a nitrogen-oxygen gas ambient. The processing resulted in an enrichment of the epi layer with oxygen. Oxygen concentration in the samples was estimated from the rate of transformation of radiation-induced interstitial carbon atoms to the interstitial carbon-interstitial oxygen defects with the use of data presented in Ref. 22. The oxygen concentration was found to be about $2 \times 10^{17} \mathrm{~cm}^{-3}$ in the epi layer. All the samples were irradiated with 4 or $6 \mathrm{MeV}$ electrons using a linear accelerator. The flux of electrons was $1 \times 10^{12} \mathrm{~cm}^{-2} \mathrm{~s}^{-1}$, and the temperature of the samples during irradiation did not exceed $50^{\circ} \mathrm{C}$. Thermal anneals of the irradiated structures were carried out in a furnace in a dry $\mathrm{N}_{2}$ ambient.

Current-voltage and capacitance-voltage measurements at different temperatures were carried out in order to check 
the quality of the diodes and to determine the concentration of non-compensated shallow acceptors and the distribution of electric field in the depletion region. Deep electronic levels were characterized with conventional DLTS and Laplace DLTS (LDLTS) techniques. ${ }^{23}$ The LDLTS technique with the application of constant bias voltage and two filling pulses of different magnitude (double LDLTS) was used to obtain the dependencies of electron emission rates on the electric field strength for deep level traps in the irradiated and annealed Si crystals.

\section{EXPERIMENTAL RESULTS AND DISCUSSION}

Figure 1 shows a conventional DLTS spectrum for an $\mathrm{n}^{+}-\mathrm{p}-\mathrm{p}^{+}$diode, which was subjected to irradiation with $4 \mathrm{MeV}$ electrons and a subsequent heat-treatment at $200^{\circ} \mathrm{C}$ for $30 \mathrm{~min}$. The heat-treatment at $200^{\circ} \mathrm{C}$ was used in order to remove some unknown defects producing minor DLTS peaks associated with hole traps, which were unstable at temperatures slightly above $350 \mathrm{~K}$ and were not relevant to the present study. All the peaks seen in the DLTS spectra are related to radiation-induced defects. The heat-treatment at $200^{\circ} \mathrm{C}$ has also resulted in the removal of the interstitial boron-interstitial oxygen $\left(\mathrm{B}_{\mathrm{i}} \mathrm{O}_{\mathrm{i}}\right)$ defect with its donor level in the upper half of the gap, which is not seen in conventional DLTS in p-type Si but can be detected using minority carrier techniques. ${ }^{24-26}$ The disappearance of the $\mathrm{B}_{\mathrm{i}} \mathrm{O}_{\mathrm{i}}$ center has been accompanied by the appearance of a DLTS peak with a peak maximum at about $151 \mathrm{~K}$, which is thought to be related to the interstitial boron-substitutional carbon complex. ${ }^{27}$ The DLTS spectrum shown in Fig. 1, resembles those reported in the literature for electron-irradiated boron-doped oxygen-rich Si crystals. ${ }^{15,18,24-28}$ We have determined electronic signatures \{activation energy for hole (electron) emission $\left[E_{\mathrm{h}(\mathrm{e})}\right]$ and pre-exponential factor $\left.(\alpha)\right\}$ for the dominant traps from Arrhenius plots of $\mathrm{T}^{2}$-corrected hole emission

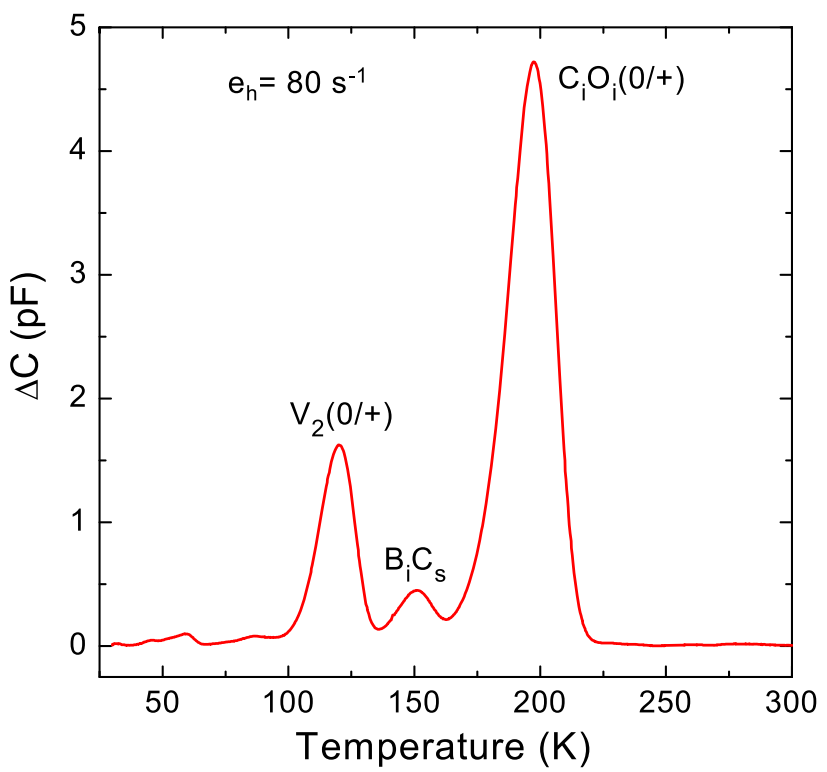

FIG. 1. DLTS spectrum for $\mathrm{a} \mathrm{n}^{+}-\mathrm{p}^{-\mathrm{p}^{+}}$diode on epi-Si, which was irradiated with $4 \mathrm{MeV}$ electrons and annealed for $15 \mathrm{~min}$ at $200^{\circ} \mathrm{C}$. Dose of irradiation was $1 \times 10^{15} \mathrm{~cm}^{-2}$. Measurement settings were: $e_{\mathrm{h}}=80 \mathrm{~s}^{-1}$, bias $-10.0 \rightarrow$ $-1.0 \mathrm{~V}$, and pulse duration $1 \mathrm{~ms}$. rates measured with the use of LDLTS. A comparison of the derived values for hole traps responsible for the dominant peaks with maxima at $120 \mathrm{~K}\left(E_{\mathrm{h}}=0.192 \mathrm{eV}\right.$, $\left.\alpha=7.4 \times 10^{5} \mathrm{~s}^{-1} \mathrm{~K}^{-2}\right) \quad$ and $197 \mathrm{~K} \quad\left(E_{\mathrm{h}}=0.360 \mathrm{eV}\right.$, $\alpha=4.0 \times 10^{6} \mathrm{~s}^{-1} \mathrm{~K}^{-2}$ ) in the spectrum with those known from the literature for radiation-induced defects in $\mathrm{Cz}-\mathrm{Si}$ :B crystals allows us to associate these peaks with hole emission from the singly positive charge states of $V_{2}$ and the interstitial carbon-interstitial oxygen complex, respectively. ${ }^{15,18,24-28}$ It should be noted that the removal of the $\mathrm{B}_{\mathrm{i}} \mathrm{O}_{\mathrm{i}}$ defect upon annealing at $200^{\circ} \mathrm{C}$ has not influenced significantly the concentration of $\mathrm{V}_{2}$.

In the following, we will concentrate only on the annealing behaviour of the divacancy and formation behaviour and electronic properties of hole traps, which appear simultaneously with the disappearance of $\mathrm{V}_{2}$. After anneals in the temperature range $100-200{ }^{\circ} \mathrm{C}$, a small decrease in intensity of the $V_{2}$ related peak without changes in the peak position has been observed. Fig. 2 shows changes in the conventional DLTS spectra upon $30 \mathrm{~min}$ isochronal annealing in the temperature range $200-300^{\circ} \mathrm{C}$ and isothermal annealing at $240^{\circ} \mathrm{C}$. Isochronal heat-treatments in the range $225-300^{\circ} \mathrm{C}$ and annealing at $240^{\circ} \mathrm{C}$ resulted in a gradual shift of the $\mathrm{V}_{2}$ related peak to higher temperatures with a small increase in the peak magnitude after annealing at $300{ }^{\circ} \mathrm{C}$ or the final treatment at $240^{\circ} \mathrm{C}$. We have applied the Laplace DLTS technique to monitor the changes upon annealing in the emission spectra in the temperature range $120-130 \mathrm{~K}$. The changes in the Laplace DLTS spectra measured at $125 \mathrm{~K}$ after isothermal annealing steps at $240^{\circ} \mathrm{C}$ are shown in Fig. 3 . It is obvious that the disappearance of the $\mathrm{V}_{2}$ related emission peak upon annealing occurs simultaneously with the growth of another emission signal with lower emission rate. Electronic signatures of the resulting trap have been determined by averaging the values derived from Arrhenius plots of emission rates measured on a few samples after different annealing steps and found to be $E_{\mathrm{h}}=0.23 \pm 0.005 \mathrm{eV}$ and $\alpha=8.9$ $\times 10^{6} \mathrm{~s}^{-1} \mathrm{~K}^{-2}$. We will refer to this trap as the $\mathrm{H}_{230}$ trap in the following. It should be mentioned that the Laplace DLTS measurements in the temperature range $130-140 \mathrm{~K}$ shows that there is another trap with its formation behaviour being very similar to that of the $\mathrm{H}_{230}$ trap. The concentration of this trap is about quarter of that for $\mathrm{H}_{230}$ and its electronic signatures are $E_{\mathrm{h}}=0.235 \pm 0.005 \mathrm{eV}$ and $\alpha=2.0 \times 10^{6} \mathrm{~s}^{-1} \mathrm{~K}^{-2}$.

Fig. 2 shows that two peaks with their maxima at about $53 \mathrm{~K}$ and $73 \mathrm{~K}$ gradually grow with increases in annealing temperature or annealing time at $240{ }^{\circ} \mathrm{C}$. The magnitude of the peak with its maximum at $53 \mathrm{~K}$ after the final heattreatments is close to that of the $\mathrm{V}_{2}$ related peak after annealing at $200^{\circ} \mathrm{C}$. The average values of electronic signatures of the traps with their peak maxima at $53 \mathrm{~K}$ and $73 \mathrm{~K}$ have been determined as $E_{\mathrm{h}}=0.08 \pm 0.005 \mathrm{eV}$ and $\alpha=2.0 \times 10^{6} \mathrm{~s}^{-1}$ $\mathrm{K}^{-2}$, and $E_{\mathrm{h}}=0.12 \pm 0.005 \mathrm{eV}$ and $\alpha=5.0 \times 10^{6} \mathrm{~s}^{-1} \mathrm{~K}^{-2}$, respectively. These traps will be referred to as the $\mathrm{H}_{80}$ and $\mathrm{H}_{120}$ traps in the following.

Changes in concentrations of the divacancy and the centers responsible for the $\mathrm{H}_{80}$ and $\mathrm{H}_{230}$ traps upon isochronal annealing and isothermal annealing at $240^{\circ} \mathrm{C}$ are shown in Figs. 4 and 5. The changes in concentration of the $\mathrm{H}_{80}$ and 

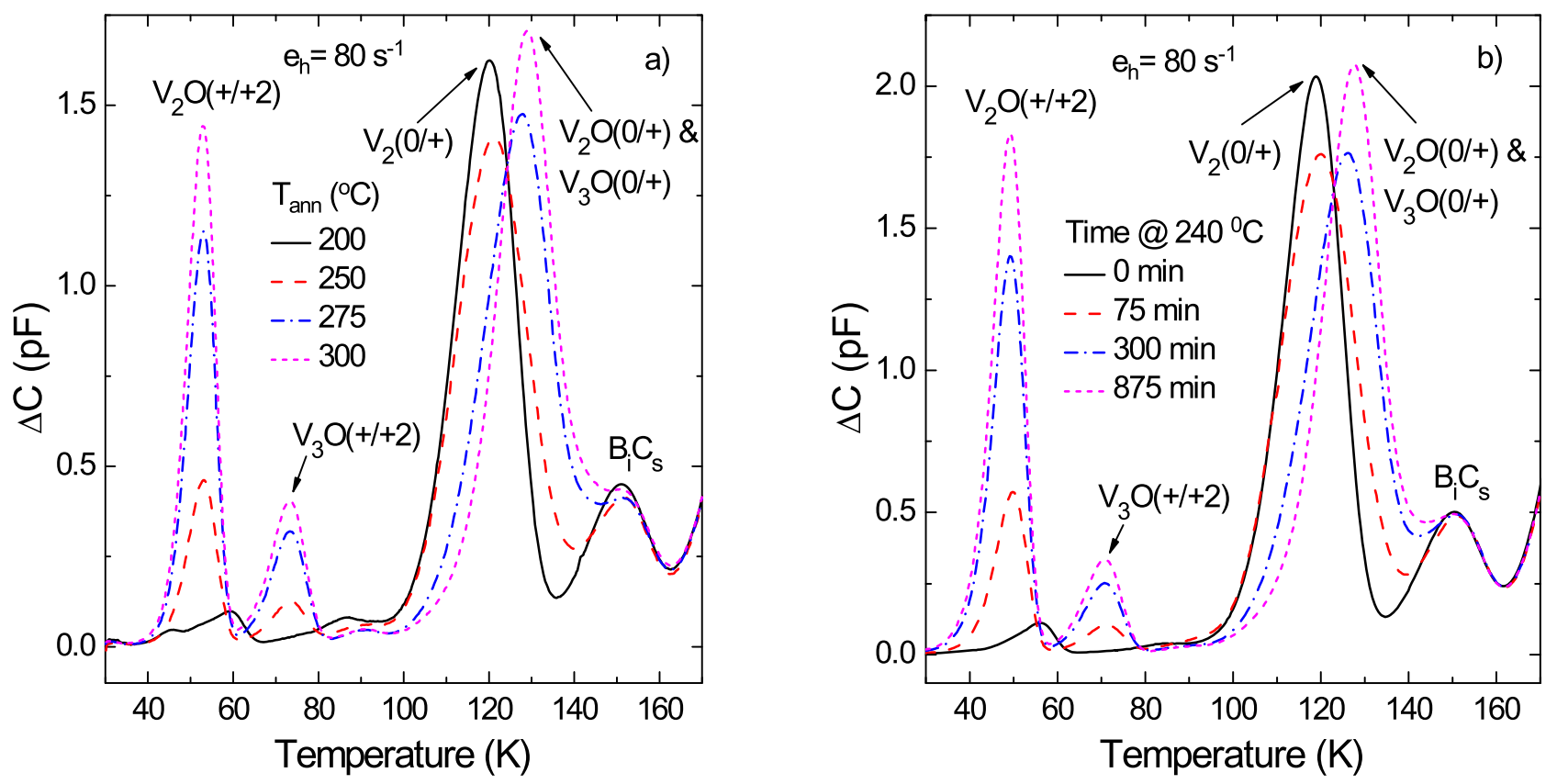

FIG. 2. Development of DLTS spectra upon (a) 30 min isochronal annealing and (b) isothermal annealing at $240{ }^{\circ} \mathrm{C}$ for electron-irradiated $\mathrm{n}^{+}$-p-p $\mathrm{p}^{+}$diodes on epi-Si. Doses of irradiation were $8 \times 10^{14} \mathrm{~cm}^{-2}$ and $1 \times 10^{15} \mathrm{~cm}^{-2}$ for the samples the spectra of which are shown in Figs. 2(a) and 2(b), respectively. Measurement settings were: $e_{\mathrm{h}}=80 \mathrm{~s}^{-1}$, bias $-10.0 \rightarrow-1.0 \mathrm{~V}$, and pulse duration $1 \mathrm{~ms}$.

$\mathrm{H}_{230}$ traps are identical and there is a clear anti-correlation in their changes with those of the $\mathrm{V}_{2}$ center. It can be concluded from the analysis of the data presented in Figs. 4 and 5 that the $\mathrm{H}_{80}$ and $\mathrm{H}_{230}$ traps are related to two energy levels of the same defect and this defect is formed at the expense of the $\mathrm{V}_{2}$ center. Considering now the impurity content of the samples studied and available results on the divacancy annealing in different silicon samples (Refs. 9, 10, 15, 17, and 18) it can be stated that the $\mathrm{H}_{230}$ and $\mathrm{H}_{80}$ traps are related to the

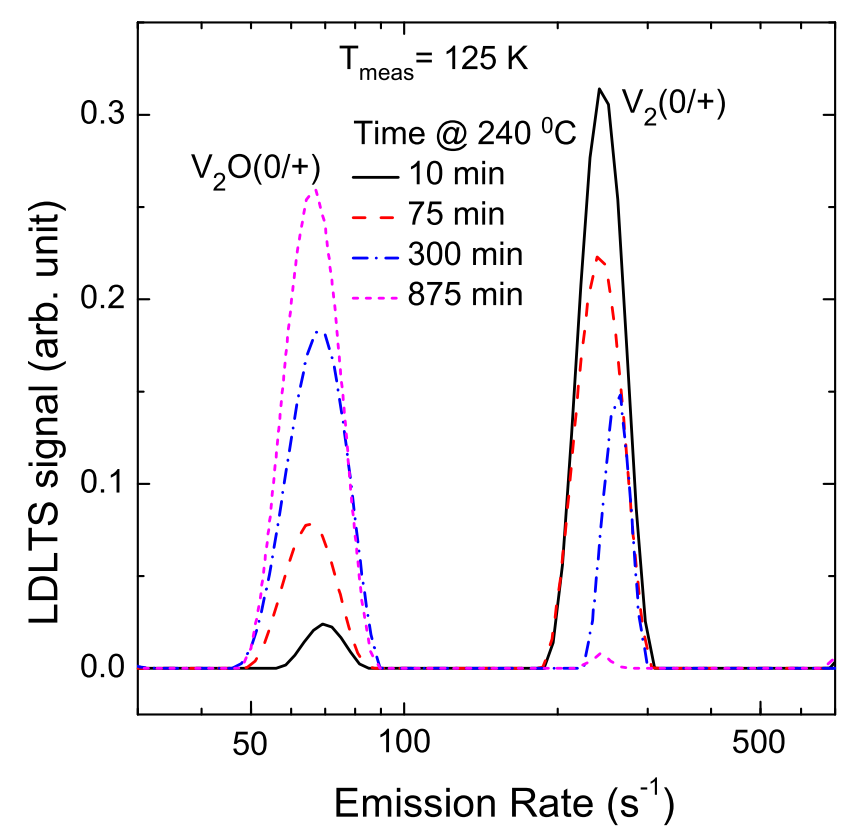

FIG. 3. Development of Laplace DLTS spectra measured at $125 \mathrm{~K}$ on an electron-irradiated $\mathrm{n}^{+}-\mathrm{p}-\mathrm{p}^{+}$diode on epi-Si upon its isothermal annealing at $240^{\circ} \mathrm{C}$. Dose of irradiation was $1 \times 10^{15} \mathrm{~cm}^{-2}$. Measurement settings were: bias $-10.0 \rightarrow-1.0 \mathrm{~V}$ and pulse duration $1 \mathrm{~ms}$. first and second donor levels of the divacancy-oxygen complex.

The $\mathrm{H}_{235}$ and $\mathrm{H}_{120}$ traps were previously suggested to be related to the first and second donor levels of the trivacancy-oxygen $\left(\mathrm{V}_{3} \mathrm{O}\right)$ defect. ${ }^{18}$ Results obtained in the present work confirm the validity of this suggestion. It was shown in our previous studies that the annealing behaviours of the $V_{2}$ and $V_{3}$ defects are very similar in oxygen-rich n-type crystals. ${ }^{11,29}$ The present work shows that the same situation occurs in oxygen-rich p-type Si crystals.

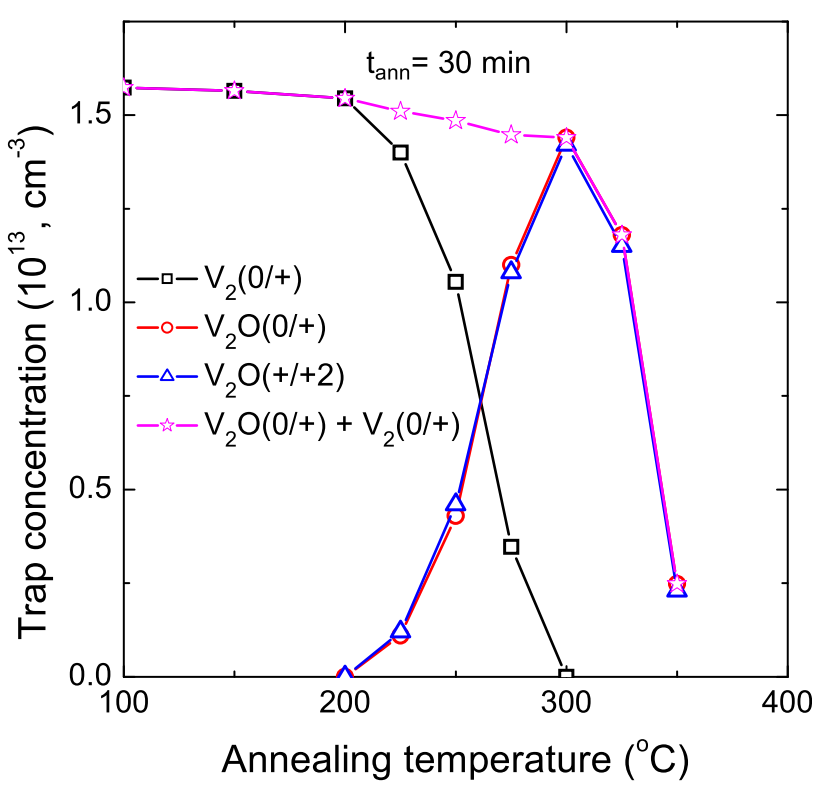

FIG. 4. Changes in concentration of $\mathrm{V}_{2}$ related complexes upon $30 \mathrm{~min}$ isochronal annealing of an electron-irradiated $n^{+}-p-p^{+}$diode on epi-Si. Dose of irradiation was $8 \times 10^{14} \mathrm{~cm}^{-2}$. 


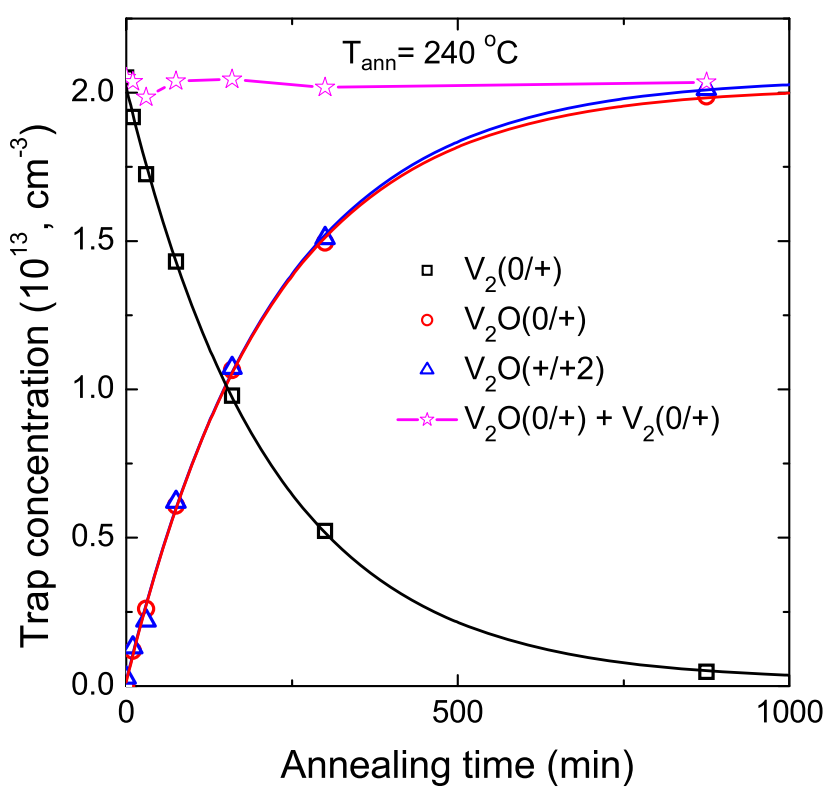

FIG. 5. Changes in concentration of $\mathrm{V}_{2}$ related complexes upon isothermal annealing at $240^{\circ} \mathrm{C}$ of an electron-irradiated $n^{+}-\mathrm{p}-\mathrm{p}^{+}$diode on epi-Si. Dose of irradiation was $1 \times 10^{15} \mathrm{~cm}^{-2}$. Solid lines are calculated with the use of mono-exponential decay and growth functions with parameters adjusted for the best fits to the experimental data.

It has been found that significant broadening occurs for the Laplace DLTS signals related to hole emission from the doubly positively charged states of the $\mathrm{V}_{2} \mathrm{O}$ and $\mathrm{V}_{3} \mathrm{O}$ complexes. One of the reasons for such broadening could be an enhancement of the hole emission rates by electric field in the diodes. We have carried out a detailed study of the effect of electric field on the hole emission rates for the states related to the $\mathrm{V}_{2} \mathrm{O}$ and $\mathrm{V}_{3} \mathrm{O}$ defects. Fig. 6 shows how the electric field in a diode studied affects the hole emission rate from the doubly positively charged state of the $\mathrm{V}_{2} \mathrm{O}$ center. The Laplace DLTS spectra shown were measured at $55 \mathrm{~K}$ on an irradiated $\mathrm{Si}$ sample, which was subjected to isothermal annealing for $15 \mathrm{~h}$ at $240{ }^{\circ} \mathrm{C}$, so, nearly all the $\mathrm{V}_{2}$ defects were transformed into the $\mathrm{V}_{2} \mathrm{O}$ complexes. The spectra were recorded with the application of a bias voltage of $-9.5 \mathrm{~V}$ and two filling pulses with a $1 \mathrm{~V}$ difference between their magnitudes. Changes in magnitudes of filling pulses result in significant changes in hole emission rate for the $\mathrm{V}_{2} \mathrm{O}^{+2}$ state reflecting the different magnitude of electric field in the parts of the depletion region sampled in the measurements.

On the basis of capacitance-voltage measurements the distribution of electric field in the depletion region of the reverse biased diode has been calculated. Fig. 7 shows a dependence of hole emission rate versus electric field strength, $e_{\mathrm{h}}(E)$, for the $\mathrm{V}_{2} \mathrm{O}^{+2}$ state together with the $e_{\mathrm{h}}(E)$ dependencies for the doubly positively charged state of the $\mathrm{V}_{3} \mathrm{O}$ complex and for the singly positively charged state of the $\mathrm{V}_{2} \mathrm{O}$ center. The electric field only weakly influences the hole emission rate from the $\mathrm{V}_{2} \mathrm{O}^{+}$state but significantly enhances the emission rates from doubly positively charged states of both the $\mathrm{V}_{2} \mathrm{O}$ and $\mathrm{V}_{3} \mathrm{O}$ complexes.

It has been shown in Refs. 30-32 that in the range of moderate electric fields $\left\{5 \times 10^{3}(\mathrm{~V} / \mathrm{cm})<\mathrm{E} \leq 5 \times 10^{4}\right.$ $(\mathrm{V} / \mathrm{cm})\}$, phonon assisted tunneling is the dominant

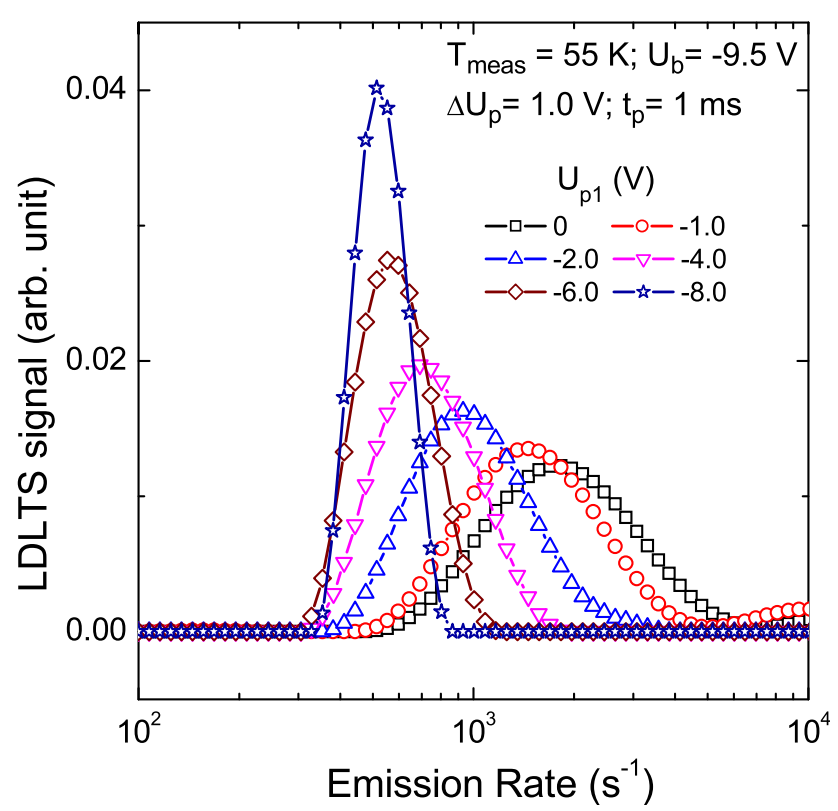

FIG. 6. Laplace DLTS spectra measured at $55 \mathrm{~K}$ for an electron-irradiated $\mathrm{n}^{+}-\mathrm{p}-\mathrm{p}^{+}$diode on epi-Si, which was annealed at $240^{\circ} \mathrm{C}$ for $15 \mathrm{~h}$. Dose of irradiation was $1 \times 10^{15} \mathrm{~cm}^{-2}$. The dominant peak in the spectra is related to electron emission from the doubly positively charged state of the divacancyoxygen center. The spectra were recorded using the double LDLTS technique with the following settings: $U_{\mathrm{b}}=-9.5 \mathrm{~V}, U_{\mathrm{p} 1}-U_{\mathrm{p} 2}=1.0 \mathrm{~V}$, and $t_{\mathrm{p}(1,2)}=1 \mathrm{~ms}$ for all the spectra. The legend shows $U_{\mathrm{p} 1}$ values for the corresponding spectra.

mechanism of electric-field enhancement of carrier emission for a number of deep level traps. Phonon assisted tunneling is characterized by an exponential increase of the carrier emission rate with the square of the electric field strength, $e(E) \sim \exp \left(E^{2}\right)$. To check the applicability of the phonon

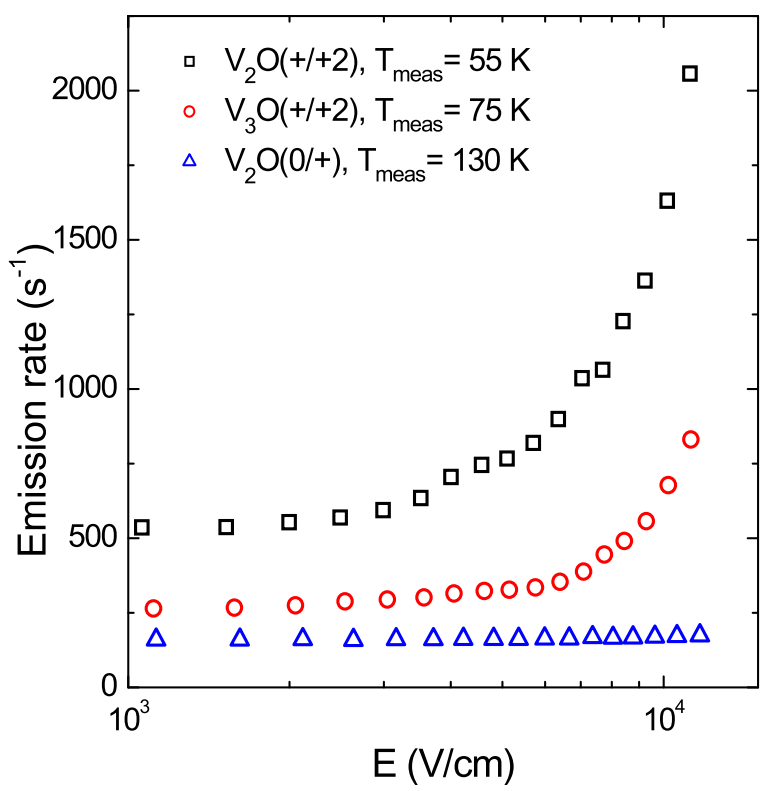

FIG. 7. Dependencies of the rate of hole emission from the single and double donor states of the $\mathrm{V}_{2} \mathrm{O}$ center and double donor state of the $\mathrm{V}_{3} \mathrm{O}$ center versus electric field strength in the depletion region of a reverse-biased $\left(U_{\mathrm{b}}=-9.5 \mathrm{~V}\right)$ electron-irradiated $\mathrm{n}^{+}-\mathrm{p}-\mathrm{p}^{+}$diode on epi-Si, which was annealed at $240^{\circ} \mathrm{C}$ for $15 \mathrm{~h}$. The values of electron emission rate have been determined from the LDLTS spectra, which were recorded with the application of the double LDLTS technique. 
assisted tunneling mechanism to the observed electric field enhancement of electron emission from the $\mathrm{V}_{2} \mathrm{O}^{+2}$ and $\mathrm{V}_{3} \mathrm{O}^{+2}$ states in $\mathrm{Si}$, we have re-plotted the data presented in Fig. 7 within $\ln \left(e_{\mathrm{h}}\right) \sim \mathrm{f}\left(E^{2}\right)$ coordinates. Fig. 8 shows the $\ln \left(e_{\mathrm{h}}\right) \sim \mathrm{f}\left(E^{2}\right)$ dependencies for the $\mathrm{V}_{2} \mathrm{O}^{+2}$ and $\mathrm{V}_{3} \mathrm{O}^{+2}$ states. In the range of electric fields from $4 \times 10^{3} \mathrm{~V} / \mathrm{cm}$ to $1.2 \times 10^{4} \mathrm{~V} / \mathrm{cm}$ the $\ln \left(e_{\mathrm{n}}\right)$ values are linearly proportional to $E^{2}$. However, at $E<4 \times 10^{3} \mathrm{~V} / \mathrm{cm}$ there is a pronounced deviation from the linearity of the $\ln \left(e_{\mathrm{n}}\right) \sim \mathrm{f}\left(E^{2}\right)$ dependencies for both the states.

The experimental results in Fig. 8 indicate that phonon assisted tunneling can be considered as the mechanism responsible for the electric-field-induced enhancement of electron emission from the doubly positively charged states of the $\mathrm{V}_{2} \mathrm{O}$ and $\mathrm{V}_{3} \mathrm{O}$ centers in the range of electric fields from $4 \times 10^{3} \mathrm{~V} / \mathrm{cm}$ to $1.2 \times 10^{4} \mathrm{~V} / \mathrm{cm}$. According to Refs. 30-32, this mechanism is characterized by the following dependence of carrier emission rate on the electric field strength

$$
e(E) / e(0)=\exp \left(\frac{E^{2}}{E_{c h}^{2}}\right),
$$

where $E_{c h}$ is a characteristic field strength, given by

$$
E_{c h}=\sqrt{\frac{3 m^{*} h}{2 \pi e^{2} \tau_{2}^{3}}},
$$

where $m^{*}$ is the effective mass of charge carriers, e is the elementary charge of the electron, and $\tau_{2}$ is the tunneling time given by

$$
\tau_{2}=\frac{h}{2 \pi k_{B} T} \pm \tau_{1},
$$

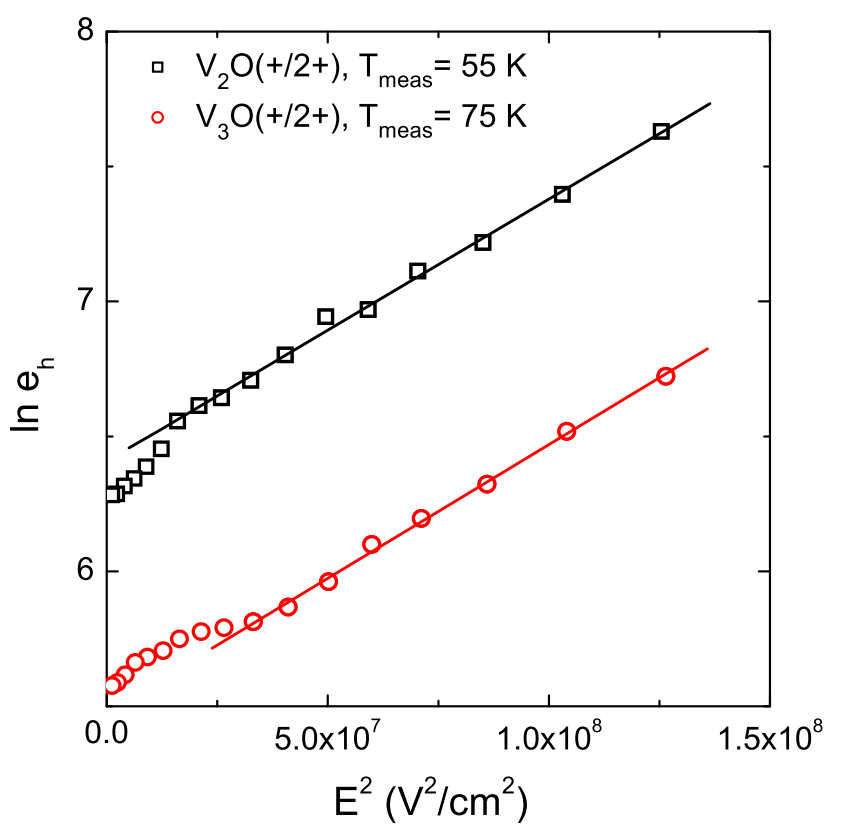

FIG. 8. Dependencies of the logarithm of the rate of hole emission from the double donor state of the $\mathrm{V}_{2} \mathrm{O}$ and $\mathrm{V}_{3} \mathrm{O}$ centers on square of static electric field in the space charge region of an $n^{+}-p-p^{+}$diode on epi-Si, which was annealed at $240^{\circ} \mathrm{C}$ for $15 \mathrm{~h}$. The straight lines correspond to $e(E)=e(0) \exp \left(E^{2} / E_{\mathrm{ch}}{ }^{2}\right)$ dependencies fitted to the experimental data for $E>5 \times 10^{3} \mathrm{~V} / \mathrm{cm}$. where the plus and minus signs correspond to the adiabatic potential structures for on-site and autolocalized centers, respectively, ${ }^{31}$ and $T$ is the temperature. The time constant $\tau_{1}$ is of the order of the inverse local impurity vibration frequency. ${ }^{31}$

From the analysis of slopes of the $\ln \left(e_{\mathrm{n}}\right) \sim \mathrm{f}\left(E^{2}\right)$ dependencies in Fig. 8, we have derived the values of $E_{c h}$ for the emissions being studied and have calculated values of $\tau_{2}$ in accordance with the Eq. (2). It appears that the $\tau_{2}$ values obtained are characteristic of centers having an on-site adiabatic potential structure and the $\tau_{1}$ values for the $\mathrm{V}_{2} \mathrm{O}$ and $\mathrm{V}_{3} \mathrm{O}$ defects are very close $\left\{\tau_{1}=(6-10) \times 10^{-14} \mathrm{~s}\right\}$.

In the range of low electric fields $\left(<4 \times 10^{3} \mathrm{~V} / \mathrm{cm}\right)$ deviations from the phonon-assisted tunnelling mechanism of the electric-field enhancement of electron emissions have been observed for the traps studied (Fig. 8). In this range of electric field the $e(E)$ dependencies might be described by another mechanism rather than phonon assisted tunnelling.

It should be also noted that for the traps with a strong dependence of carrier emission rate on electric field, a significant decrease in the magnitudes of the corresponding emission peaks in conventional DLTS spectra could occur. ${ }^{33} \mathrm{~A}$ smaller magnitude of the peak related to the $\mathrm{V}_{2} \mathrm{O}(+2 /+)$ transition compared to that for the $\mathrm{V}_{2} \mathrm{O}(+/ 0)$ transition (Fig. 2 ) is partially related to the effect of electric field on hole emission rate from the doubly positively charged state of the $\mathrm{V}_{2} \mathrm{O}$ center and, consequently, on the magnitude of the $\mathrm{V}_{2} \mathrm{O}(+2 /+)$ transition. When analysing the changes in concentrations of the $\mathrm{V}_{2}$ related peaks upon annealing (Figs. 4 and 5) we have used data for the magnitudes of the corresponding transients obtained from the Laplace DLTS measurements, which give the correct values of the magnitudes of capacitance transients.

\section{CONCLUSIONS}

We have observed a clear anti-correlation between the disappearance of $\mathrm{V}_{2}$ and the appearance of two hole traps with the activation energies for hole emission being $0.23 \mathrm{eV}$ and $0.08 \mathrm{eV}$ upon isochronal and isothermal annealing of electron-irradiated oxygen-rich p-type Si crystals. It is argued that these traps are related to the first and second donor levels of the divacancy-oxygen $\left(\mathrm{V}_{2} \mathrm{O}\right)$ complex, respectively. It has been found that significant electric-field-induced enhancement of hole emission from the second donor level of the $\mathrm{V}_{2} \mathrm{O}$ and $\mathrm{V}_{3} \mathrm{O}$ centers occurs in the diodes studied. In the range of electric field from $4 \times 10^{3}$ to $1.2 \times 10^{4} \mathrm{~V} / \mathrm{cm}$, the emission enhancement is associated with phonon-assisted tunnelling.

\section{ACKNOWLEDGMENTS}

The Engineering and Physical Sciences Research Council (EPSRC) UK and the Fund for Fundamental Research of the Republic of Belarus (grant F12MC-009) are thanked for their financial support.

${ }^{1}$ S. D. Brotherton and P. Bradley, J. Appl. Phys. 53, 5720 (1982).

${ }^{2}$ A. Hallén, N. Keskitalo, F. Masszi, and V. Nagl, J. Appl. Phys. 79, 3906 (1996). 
${ }^{3}$ A. Ali, T. Gouveas, M. A. Hasan, H. S. Zaidi, and M. Asghar, Sol. Energy Mater. Sol. Cells 95, 2805 (2011).

${ }^{4}$ G. D. Watkins and J. W. Corbett, Phys. Rev. 138, A543 (1965).

${ }^{5}$ B. G. Svensson, Properties of Crystalline Silicon, EMIS Data Review Series Vol. 20, edited by R. Hull (INSPEC, London, 1999), p. 763.

${ }^{6}$ L. C. Kimerling, Radiation Effects in Semiconductors 1976, Inst. Phys. Conf. Ser. Vol. 31, edited by N. B. Urli and J. W. Corbett (IOP, Bristol, London, 1977), p. 221.

${ }^{7}$ A. O. Evwarye and E. Sun, J. Appl. Phys. 47, 3776 (1976).

${ }^{8}$ B. G. Svensson, B. Mohadjeri, A. Hallén, J. H. Svensson, and J. W. Corbett, Phys. Rev. B 43, 2292 (1991).

${ }^{9}$ V. P. Markevich, A. R. Peaker, S. B. Lastovskii, L. I. Murin, and J. L. Lindström, J. Phys.: Condens. Matter 15, S2779 (2003).

${ }^{10}$ M. Mikelsen, E. V. Monakhov, G. Alfieri, B. S. Avset, and B. G. Svensson, Phys. Rev. B 72, 195207 (2005).

${ }^{11}$ J. Coutinho, V. P. Markevich, A. R. Peaker, B. Hamilton, S. B. Lastovskii, L. I. Murin, B. G. Svensson, M. J. Rayson, and P. R. Briddon, Phys. Rev. B 86, 174101 (2012).

${ }^{12}$ G. S. Hwang and W. A. Goddard III, Phys. Rev. B 65, 233205 (2002).

${ }^{13}$ L. J. Cheng, J. C. Corelli, J. W. Corbett, and G. D. Watkins, Phys. Rev. 152, 761 (1966)

${ }^{14}$ Y.-H. Lee and J. W. Corbett, Phys. Rev. B 13, 2653 (1976).

${ }^{15}$ M.-A. Trauwaert, J. Vanhellemont, H. E. Maes, A.-M. Van Bavel, G. Langouche, and P. Clauws, Appl. Phys. Lett. 66, 3056 (1995).

${ }^{16}$ J. L. Lindström, L. I. Murin, V. P. Markevich, T. Hallberg, and B. G. Svensson, Physica B 273-274, 291 (1999).

${ }^{17}$ G. Alfieri, E. V. Monakhov, B. S. Avset, and B. G. Svensson, Phys. Rev. B 68, 233202 (2003).

${ }^{18}$ V. P. Markevich, A. R. Peaker, B. Hamilton, S. B. Lastovskii, L. I. Murin, J. Coutinho, V. J. B. Torres, L. Dobaczewski, and B. G. Svensson, Phys. Status Solidi A 208, 568 (2011)
${ }^{19}$ N. Ganagona, B. Raeissi, L. Vines, E. V. Monakhov, and B. G. Svensson, J. Phys.: Condens. Matter 24, 435801 (2012).

${ }^{20}$ N. Ganagona, B. Raeissi, L. Vines, E. V. Monakhov, and B. G. Svensson, Phys. Status Solidi C 9, 2009 (2012).

${ }^{21}$ I. Pintilie, E. Fretwurst, G. Lindstrom, and J. Stahl, Appl. Phys. Lett. 81, 165 (2002).

${ }^{22}$ V. P. Markevich and L. I. Murin, Sov. Phys. Semicond. 21, 767 (1987).

${ }^{23}$ L. Dobaczewski, A. R. Peaker, and K. B. Nielsen, J. Appl. Phys. 96, 4689 (2004).

${ }^{24}$ P. M. Mooney, L. G. Cheng, M. Suli, G. D. Gerson, and J. W. Corbett, Phys. Rev. B 15, 3836 (1977).

${ }^{25}$ A. Khan, M. Yamaguchi, M. Kaneiwa, T. Saga, T. Abe, O. Annzawa, and S. Matsuda, J. Appl. Phys. 87, 8389 (2000).

${ }^{26}$ L. Vines, E. V. Monakhov, A. Yu. Kuznetsov, R. Kozlowski, P. Kaminski, and B. G. Svensson, Phys. Rev. B 78, 085205 (2008).

${ }^{27}$ L. C. Kimerling, M. T. Asom, J. L. Benton, P. J. Drevinsky, and C. E. Kaefer, Mater. Sci. Forum 38-41, 141 (1989).

${ }^{28}$ V. P. Markevich, L. I. Murin, S. B. Lastovskii, I. F. Medvedeva, B. A. Komarov, J. L. Lindström, and A. R. Peaker, J. Phys.: Condens. Matter 17, S2331 (2005).

${ }^{29}$ V. P. Markevich, A. R. Peaker, S. B. Lastovskii, L. I. Murin, J. Coutinho, V. J. B. Torres, P. R. Briddon, L. Dobaczewski, E. V. Monakhov, and B. G. Svensson, Phys. Rev. B 80, 235207 (2009)

${ }^{30}$ S. D. Ganichev, W. Prettl, and P. G. Huggard, Phys. Rev. Lett. 71, 3882 (1993).

${ }^{31}$ S. D. Ganichev, W. Prettl, and I. N. Yassievich, Fiz. Tverd. Tela (St. Petersburg) 39, 1905 (1997); Phys. Solid State 39, 1703 (1997)].

${ }^{32}$ S. D. Ganichev, E. Ziemann, W. Prettl, I. N. Yassievich, A. A. Istratov, and E. R. Weber, Phys. Rev. B 61, 10361 (2000).

${ }^{33}$ B. A. Komarov, F. P. Korshunov, and L. I. Murin, Sov. Phys. Semicond. 28, 305 (1994). 